\title{
Modeling the hydrodynamic interactions between the main channel and the floodplain at McCarran Ranch in the lower Truckee River, Nevada
}

\author{
X. Chen ${ }^{1}$, L. Chen ${ }^{1,3}$, J. Zhao ${ }^{2}$, and Z. Yu ${ }^{1}$ \\ ${ }^{1}$ State Key Laboratory of Hydrology-Water Resources and Hydraulic Engineering, Hohai University, \\ Nanjing 210098, China \\ ${ }^{2}$ College of Water Conservancy and Hydropower Engineering, Hohai University, Nanjing 210098, China \\ ${ }^{3}$ Division of Hydrologic Sciences, Desert Research Institute, Las Vegas, 89119, USA
}

Correspondence to: L. Chen (1chen@dri.edu)

Received: 1 April 2014 - Published in Nat. Hazards Earth Syst. Sci. Discuss.: 27 May 2014

Revised: 14 September 2015 - Accepted: 16 September 2015 - Published: 30 September 2015

\begin{abstract}
This study applied the two-dimensional AdH (adaptive hydraulics) hydrodynamic model to a river reach to analyze flood hydraulics on complex floodplains. Using the AdH model combined with bathymetry and topographic data from the United States Geological Survey (USGS) seamless server and the United States Army Corps of Engineers (USACE), we intended to examine the interactions between the channel and floodplain of a $10 \mathrm{~km}$ stretch at McCarran Ranch, which is located at the lower Truckee River in Nevada. After calibrating the model, we tested the dependence of the modeling results on mesh density, input parameters, and time steps and compared the modeling results to the existing gauged data (both the discharge and water stage heights). Results show that the accuracy of prediction from the AdH model may decline slightly at higher discharges and water levels. The modeling results are more sensitive to the roughness coefficient of the main channel, which suggests that the model calibration should give priority to the main channel roughness. A detailed analysis of the floodwater dynamics was then conducted using the modeling approach to examine the hydraulic linkage between the main channel and floodplains. We found that large flood events could lead to a significantly higher proportion of total flow being routed through the floodplains. During peak discharges, a river channel diverted as much as $65 \%$ of the total discharge into the floodplain. During the periods of overbank flow, the transboundary flux ratio was approximately 5 to $45 \%$ of the total river discharge, which indicates substantial exchange between the main channel and floodplains. The results also
\end{abstract}

showed that both the relations of the inundation area and volume versus the discharge exhibit an apparent looped curve form, which suggests that flood routing has an areal hysteresis effect on floodplains.

\section{Introduction}

The hydrodynamic characteristics of floods are important to hydraulics, fluvial geomorphology, and aquatic ecosystems because they affect water resources issues such as flood control, river-bank erosion, sedimentation, and freshwater habitat restoration. In streams with large floodplains, floods might exhibit more complex flow patterns because the overbank flow could be very different from the channel flow and the hydraulic interaction between the floodplains and the main channel could be complicated. The dynamic linkage between the channel and the floodplain during floods can greatly affect floodwaters, sediment transport, erosion, and deposition on floodplains with unsteady, nonuniform flow features (Amoros and Bornette, 2002; Antheunisse and Verhoeven, 2008; Bridge, 2003; Thoms, 2003; Sheldon et al., 2002; Stanford and Ward, 1993). This linkage might affect not only the flood conveyance and flood risks, but also influence water quality and ecological processes in the river system.

The pattern of flood inundation is critical to vegetation distribution in the floodplains (Galat, 1990; McKenna et al., 1992). Temporal and spatial changes in flood inunda- 
tion extent and water level play a crucial role in maintaining sustainable organic material/nutrient exchanges between the main channel and floodplains, and they are critical for understanding hydrological and biogeochemical processes in aquatic ecosystems (Bayley, 1995; Antheunisse and Verhoeven, 2008; Pettit et al., 2011). The ability to model potential flood inundation and map the actual extent of inundation, timing, and intensity under different flood levels is central to understanding the dynamics of ecological interactions in the main channel and floodplain system.

Numerical models of the channel and floodplain flows are important for understanding and predicting the effects of hydrodynamics on the channel and floodplain systems. Because more accurate and reliable flow and inundation predictions will allow for better decisions to be made regarding land use and water management, the development and improvement of methods for high-resolution hydrologic modeling has increased (Neal et al., 2012;). Significant advances in flood modeling have been achieved in the last decade through the use of a new generation of two-dimensional (2-D) hydraulic numerical models (Leopardi et al., 2002; Hunter et al., 2007; Neal et al., 2011). These models have the potential to predict the local pattern and timing of flood depth and velocity, which allows for more informed flood risk zoning and improved emergency planning.

Suitable models for floodplain analysis must be capable of describing the interaction between floodplain topography and unsteady, nonuniform water flow and sediment transport. In particular, numerical models should be able to describe the effect of channel curvature on floodplain flow structure and how they change over time (Bridge, 2003). Therefore, the representation of flow field in the model should be 2D or 3-D. The U.S. Army Corps of Engineers (USACE) AdH (adaptive hydraulics) model software is a 2-D, shallowwater modeling tool that is used for floodplain modeling studies (Gambucci, 2009). This tool was developed at the Coastal and Hydraulics Laboratory (CHL) and has been used to model hydrodynamics and sediment transport in sections of the Mississippi River, tidal conditions in southern California, and vessel traffic in the Houston Ship Channel. Therefore, it is suitable for analyzing the hydrodynamic interactions of channels and floodplains.

The main objective of this study was to investigate the hydrologic connectivity between floodplains and the main channel of a reach in the lower Truckee River during floods. The 2-D, AdH hydrodynamics model used in this study allowed for the detailed analysis of flood flow characteristics in the channel and floodplain system. By examining several hydrodynamic aspects of the linkage between the river and the floodplain - including the flow rate partitioning of the channel and floodplain, the transboundary flux, and the floodplain inundation dynamics - the interaction between the two main geomorphic components of rivers was assessed. The results of this study may help advance nutrient exchange and partic- ulate matter research in dynamic river and floodplain systems and their potential impacts on aquatic ecosystems.

\section{Methodology}

\subsection{Study site}

We selected the McCarran Ranch reach of the Truckee River in Nevada as our study site to investigate the hydrodynamics of main channel and floodplain systems. The Truckee River flows through California and Nevada. It is the second largest river in Nevada and the only outflow from Lake Tahoe. Roughly every 10 years, the Truckee River generates a damaging flood. The 1997 inundation was a major event that put downtown Reno under several feet of water and turned much of the Sparks industrial area into an inland sea. Although flooding is inevitable, progress is being made to control flooding and make the area less prone to such risks (http://www.truckeeflood.us/). Using satellite observations to evaluate the inundation extent and water level has been considered (Townsend and Walsh, 1998; Overton, 2005), but the satellite information that is currently available does not provide a solution because it is usually made using profiling altimeters with wide spacing between tracks (Birkett et al., 2002; Coe and Birkett, 2004), passive microwave instruments with good temporal but limited spatial resolution (Hamilton et al., 2002, 2004), or synthetic aperture radars with good spatial resolution but limited temporal coverage (Hess et al., 2003; Frappart et al., 2005). Although the regional significance of the hydrology and biogeochemistry processes in the Truckee River floodplains is undisputed, flood-risk analyses need higher accuracy at much finer spatial and temporal resolutions.

\subsection{Governing equations and model settings}

The 2-D, AdH shallow water model solves the 2-D nonlinear shallow water equations. These equations have proven successful in describing water surface and velocity fields in surface-water modeling and seem to be accepted by many authors because most studies use 2-D models (Abderrezzak et al., 2009; Mignot et al., 2006; Bates et al., 2010; deAlmeida et al., 2012). The equations are derived with the assumption that the vertical velocity component is negligible. Neglecting shear stress and fluid pressure at the free surface, the 2-D shallow water equations implemented within $\mathrm{AdH}$ are written as

$$
\frac{\partial Q}{\partial t}+\frac{\partial F_{x}}{\partial x}+\frac{\partial F_{y}}{\partial y}+H=0,
$$

where

$$
Q=\left\{\begin{array}{c}
h \\
u h \\
v h
\end{array}\right\}
$$




$$
\begin{aligned}
& F_{x}=\left\{\begin{array}{c}
u h \\
u^{2} h+\frac{1}{2} g h^{2}-h \frac{\sigma_{x x}}{\rho} \\
u v h-h \frac{\sigma_{y x}}{\rho}
\end{array}\right\} \\
& F_{y}=\left\{\begin{array}{c}
v h \\
u v h-h \frac{\sigma_{y x}}{\rho} \\
v^{2} h+\frac{1}{2} g h^{2}-h \frac{\sigma_{y y}}{\rho}
\end{array}\right\} \\
& H=\left\{\begin{array}{c}
0 \\
g h \frac{\partial z_{\mathrm{b}}}{\partial x}+n^{2} g \frac{u \sqrt{u^{2}+v^{2}}}{h^{1 / 3}} \\
g h \frac{\partial z_{\mathrm{b}}}{\partial y}+n^{2} g \frac{v \sqrt{u^{2}+v^{2}}}{h^{1 / 3}}
\end{array}\right\} .
\end{aligned}
$$

The Reynolds stresses are determined using the Boussinesq approach to the gradient in the mean currents:

$\sigma_{x x}=2 \rho v_{\mathrm{t}} \frac{\partial u}{\partial x}$

$\sigma_{y y}=2 \rho v_{\mathrm{t}} \frac{\partial v}{\partial y}$

$\sigma_{x y}=\sigma_{y x}=2 \rho v_{\mathrm{t}}\left(\frac{\partial u}{\partial y}+\frac{\partial v}{\partial x}\right)$,

where $h$ is flow depth; $u$ and $v$ are velocities in $x$ and $y$ directions; $g$ is gravitational acceleration; $\rho$ is flow density; $\sigma_{x x}, \sigma_{y y}, \sigma_{x y}$, and $\sigma_{y x}$ are shear stresses in which the first subscript indicates the direction and the second indicates the face on which the stress acts because of turbulence; $z_{\mathrm{b}}$ is the river bed elevation; $n$ is Manning's friction coefficient; and $v_{\mathrm{t}}$ is the kinematic eddy viscosity, which varies spatially where turbulence closure is achieved through the algebraic eddy viscosity formulation described by Rodi (1993).

The critical input data are from the digital elevation model (DEM) of sufficient resolution and vertical accuracy to capture floodplain topographic features that are relevant to flow development at the scale of interest and channel bathymetric information detailing the longitudinal slope. The channel bathymetry was obtained from the USACE. The floodplain topology data were created from the $30 \mathrm{~m} \times 30 \mathrm{~m}$, USGS digital elevation model (DEM) obtained from the USGS seamless server (http://seamless.usgs.gov/), which was integrated into the bathymetry data. These data are necessary for delineating the study area and assigning elevation for individual grid cells (Bates and De Roo, 2000). The modeling area is depicted in Fig. 1. The AdH model was developed for a river reach of approximately $10 \mathrm{~km}$ in length.

The other group of input parameters was the surface roughness. These parameters are generally associated with the land-use information. The land-use data were obtained from the WebGIS website (http://www.webgis.com), which were used to determine the surface roughness with reference data obtained from the tabular values in Chow et al. (1988). Fine-tuning the roughness value was carried out in model calibration. The land-use pattern within the AdH model boundary is shown in Fig. 2a. The estimated eddy viscosity function with a coefficient value of 0.5 was also used for this

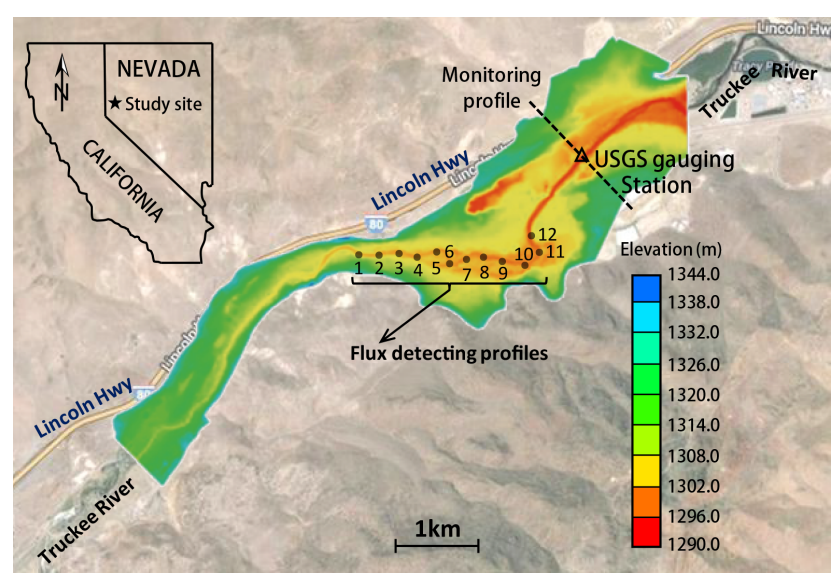

Figure 1. Study location and the elevation of focused area.

study. Because the element wetting and drying limits could cause model instabilities that require an elaborate adjustment (Gambucci, 2009; Karadogan and Willson, 2010), we set the values at $0.15 \mathrm{~m}$ for both limits. The results of testing the models showed that changes in these values have very little impact on the hydrodynamic results.

There is only one gauging station (USGS 10350340) in the study reach. This gauge is located at the lower part of the study area (Fig. 1) and it has been operating since June 1997. Data from this station were used for model validation. The nearest gauging station (USGS 10350000) is upstream to the study reach and it has been collecting data since January 1995. Data from this station were used as inputs in a HEC-RAS simulation and the output hydrograph was used as an upstream boundary condition of the study reach. For flood events that happened before June 1997, the outputs of HEC-RAS on the USGS gauging profile were used for validation. The river stage values also obtained from the HEC-RAS simulation results were used as a downstream boundary condition. The HEC-RAS model used in this study was obtained from the U.S. Army Corps of Engineers Sacramento District. It has been well calibrated and is able to give proper boundary conditions for running $\mathrm{AdH}$. The observed river flow was obtained from USGS NWIS (http://waterdata.usgs.gov/nwis/sw). It was used to compare the modeled flow with the observed flow.

\subsection{Model}

\subsubsection{Model calibration}

The model is designed to work in conjunction with the Surface-Water Modeling System (SMS), which can be used to create the mesh files directly for AdH setup. We used SMS to establish a finite element model for the chosen study area. Figure $2 \mathrm{~b}$ represents the unstructured mesh domain. For $\mathrm{a}$ higher accuracy, the mesh adaptive technology was used for mesh refinement to get better results. Generally, the number 


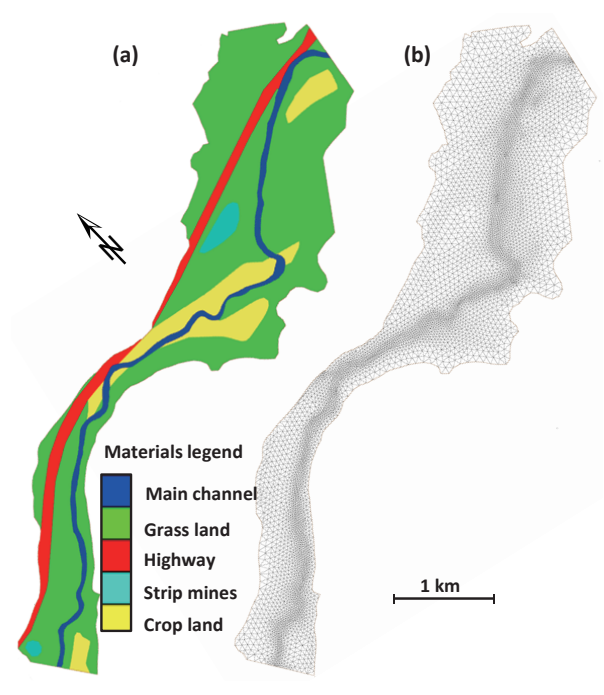

Figure 2. The land-use information (a) and finite element mesh (b) of the study area.

of finite element mesh (FEM) nodes during the interaction ranged from 6307 to 7911 . The devastating flood in early 1997 was chosen as a typical flood for model calibrations and validations. Because of the large inundation area during this flood event, it is more appropriate to analyze the impacts of floodplain roughness on the flood propagation. The roughness coefficients of the main channel and floodplains were set separately for model calibration. To examine the model response to the roughness coefficient, we ran a matrix of 25 simulations with values of $n_{\mathrm{c}}$ (roughness coefficient for the main channel) that varied from 0.036 to 0.041 in 0.001 increments and $n_{\mathrm{f}}$ (roughness coefficient for the floodplains) that varied from 0.044 to 0.05 in 0.002 increments.

The outputs of the model were compared with the observed values available at the gauging station near the outlet of the river reach. We calculated the time series discharge across the gauging profile based on the velocity magnitude and water depth value along the profile line (showing in Fig. 1). The accuracy of all of the simulations was then calculated using the Nash-Sutcliffe efficiency criteria (Nash and Sutcliffe, 1970), $E_{\mathrm{f}}$ :

$E_{\mathrm{f}}=1-\frac{\sum^{n}\left(\hat{Y}_{i}-Y_{i}\right)^{2}}{\sum^{n}\left(Y_{i}-\bar{Y}\right)^{2}}$,

in which $\hat{Y}_{i}$ and $Y_{i}$ are predicted and measured values of the criterion-dependent variable $Y$, respectively; $\bar{Y}$ is the mean of the measured values of $Y ; n$ is the sample size; and $E_{\mathrm{f}}$ ranges between $-\infty$ (where the observed mean is a better predictor than the model) and 1 (where observed and predicted values are identical). The Nash-Sutcliffe coefficient is considered to be a goodness-of-fit index to systemically assess the effectiveness of hydrological models (Krause et al., 2005;
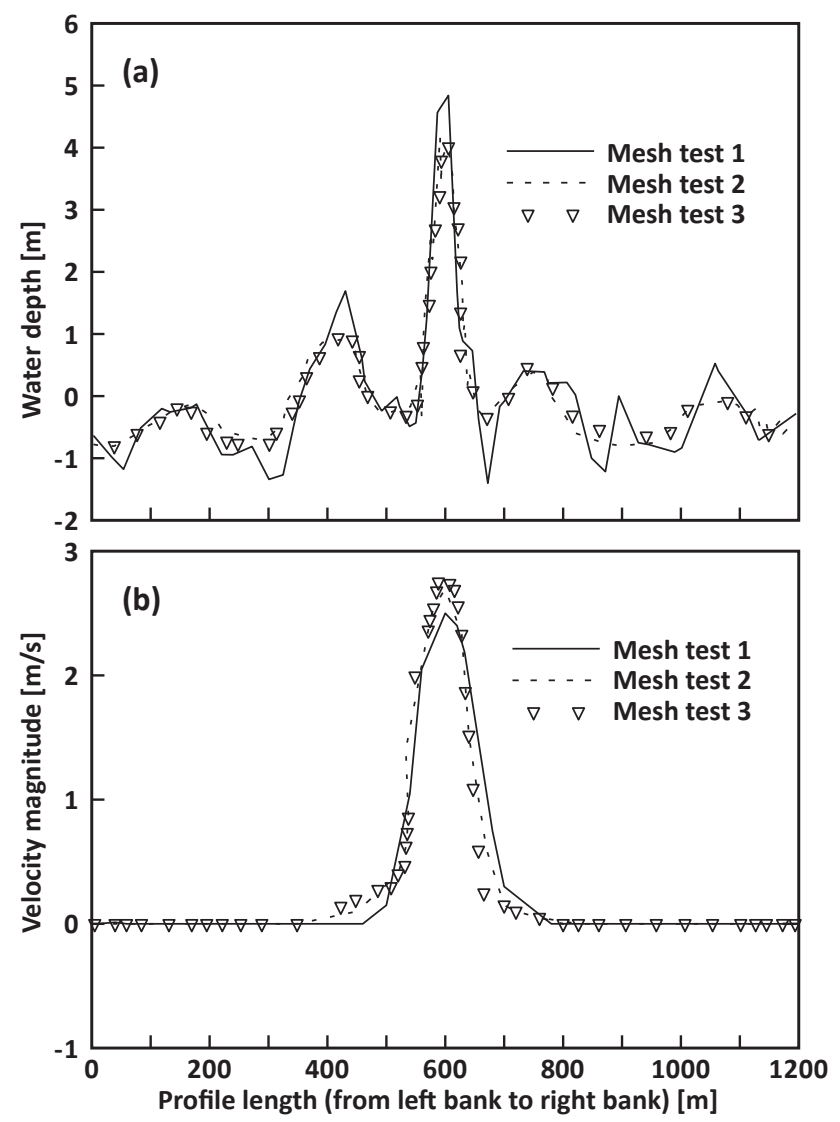

Figure 3. Results of mesh dependence testing.

McCuen et al., 2006). By calculating the $E_{\mathrm{f}}$ value for the 25 scenarios, it was found that the index value ranged from 0.770 , with the lowest main channel roughness $\left(n_{\mathrm{c}}=0.036\right)$, to 0.937 with the roughness of main channel equal to 0.039 . The change of roughness of floodplains makes less difference in the Nash-Sutcliffe index (for example, the $E_{\mathrm{f}}$ value ranges from 0.924 to 0.937 with the $n_{\mathrm{f}}$ gradually varying from 0.044 to 0.05 , while $n_{\mathrm{c}}$ is kept at a constant value of 0.039 ), which suggests that the modeled flood discharge is much more sensitive to the main channel friction than the floodplain friction. Based on this understanding of the effects of roughness, the calibrated roughness coefficient of the main channel was set to 0.039 and the roughness coefficients for other land-use types were set to 0.048 (grassland), 0.05 (cropland), 0.011 (highway), and 0.05 (strip mines). The model was validated using the adjusted roughness coefficients for the flood that occurred in early January 1997 . The corresponding $E_{\mathrm{f}}$ is equal to 0.933 , which is a satisfactory goodness of fit.

\subsubsection{Mesh dependence analysis}

The adaptive numerical mesh within the AdH model can improve model accuracy without sacrificing efficiency. Before applying the adaptive mesh approach, a base-level mesh 
Table 1. Scenarios of mesh dependence testing.

\begin{tabular}{ll}
\hline Mesh testing & No. of elements \\
\hline M1 & 4911 \\
M2 & 6307 \\
M3 & 10306 \\
\hline
\end{tabular}

needs to be generated. The mesh was created using the SMS software, which can be used as a pre- and post-processing graphic user interface for AdH. After generating the mesh, the bathymetric data of the stream were interpolated onto the mesh nodes. Triangular elements were used to discretize the domain, which is shown in Fig. 2b. Special care was taken to generate a fine mesh in the vicinity of the main channel. Because the simulation results depend on the mesh resolution and quality, several mesh resolutions were adopted for the mesh dependence study (Table 1). The simulated velocity and water depth were extracted on the profile where the USGS gauging station was located so that they could be compared with the observations. Figure $3 \mathrm{a}$ and $\mathrm{b}$ show the velocity and water depth that correspond to the different elements of the peak flow stage for a high discharge flood that happened in early January 1997 . The time step $(\Delta t)$ was set to $1 \mathrm{~s}$. The results show that the mesh sizes M2 and above were observed to be mesh-independent.

\subsubsection{Sensitivity to time steps}

The AdH is an implicit code, and therefore the model stability is not limited to time-step size for linear problems, but nonlinear instability will occur if the time step is too large (Tate et al., 2009). Choosing a proper initial time step could reduce the turnaround time for time-critical simulations. Three different initial time-step sizes were chosen for investigating the initial time-step dependence (see Table 2). As with the mesh dependence analysis, the depth and velocity values along the gauging profile at the peak flow stage in early January 1997 were used for comparison. Figure 4 shows both the velocity and depth along the gauging profile, plotted for particular time levels. From Fig. 4, it can be noted that the initial time-step sizes of $30 \mathrm{~s}$ are good enough to capture the physical properties of flood modeling results.

\section{Results and discussion}

\subsection{Model application}

The calibrated model is then used to simulate different flood events to examine the applicability and accuracy of the details of the simulations. We chose six other flood events as testing cases in addition to the flood event in early 1997 (Fig. 5). These cases were sorted by index numbers according to the magnitude of peak flow. Comparisons of the gaug-
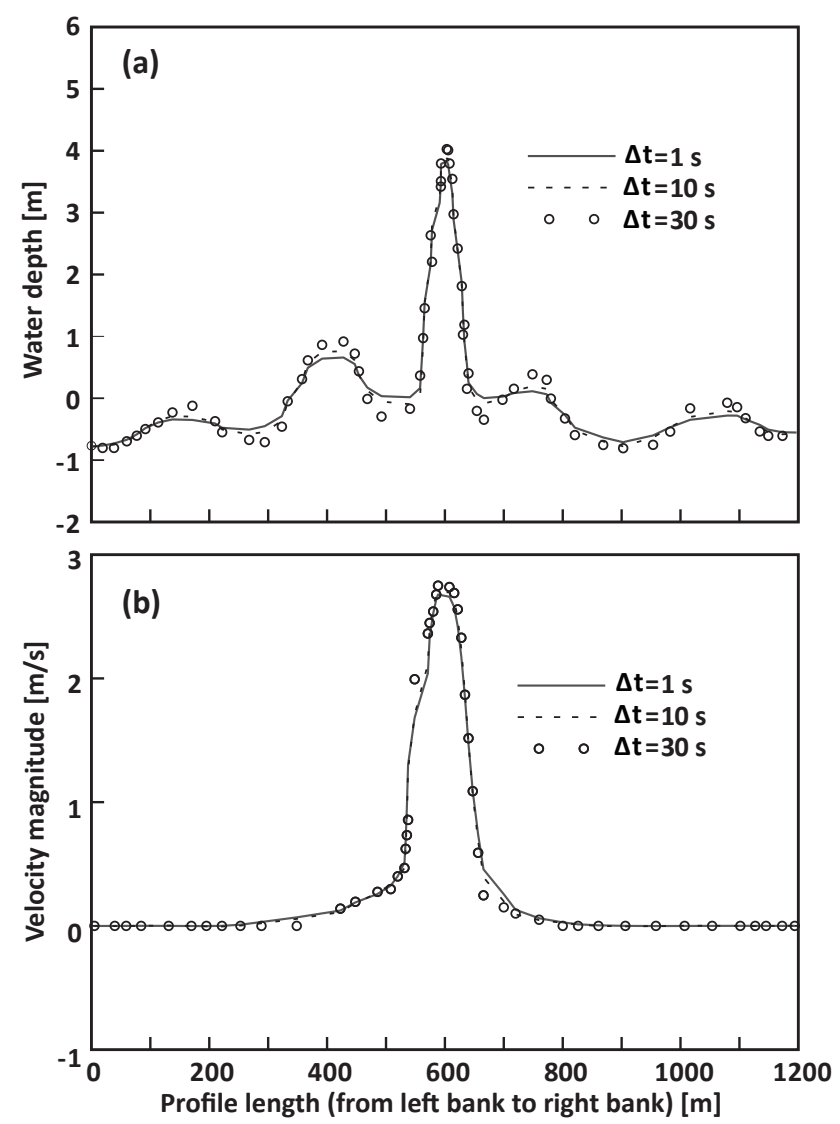

Figure 4. Results of time sensitivity study.

ing station data (both the discharge and water level) for the seven test cases are shown in Figs. 6 and 7. The scatter plot comparison of all the data is shown in the lower right corner in each figure. The root-mean-square error (RMSE), which is a commonly used accuracy measure, is calculated for each test case and shown in Figs. 6 and 7. The overall RMSE for all of the test cases to the discharge throughout the simulation was $5.83 \mathrm{~m}^{3} \mathrm{~s}^{-1}$. This was reduced to $3.06 \mathrm{~m}^{3} \mathrm{~s}^{-1}$ for discharge less than $100 \mathrm{~m}^{3} \mathrm{~s}^{-1}$ and increased to $6.94 \mathrm{~m}^{3} \mathrm{~s}^{-1}$ for discharge higher than $100 \mathrm{~m}^{3} \mathrm{~s}^{-1}$. The model predicted low flow much better (RMSE ranges 0.90 to $1.70 \mathrm{~m}^{3} \mathrm{~s}^{-1}$ for test cases 1-3) and the model performance decreased for high flow (RMSE ranges 3.13 to $14.65 \mathrm{~m}^{3} \mathrm{~s}^{-1}$ for test cases 4-7). The overall RMSE of water depth for all test cases throughout the simulation was $0.12 \mathrm{~m}$, which is similar to what is shown in Fig. 6. The accuracy of the model predictions was higher for lower water levels (RMSE was $0.07 \mathrm{~m}$ for water depth less than $3 \mathrm{~m}$ and increased to $0.13 \mathrm{~m}$ for water depth higher than $3 \mathrm{~m}$ ).

For the relatively low flow cases (testing cases 1-3), the RMSE ranged from 0.009 to $0.015 \mathrm{~m}$, which shows good accuracy for predictions at low water levels. The RMSE for the relevant higher flow (testing cases 4-7) ranged from 0.05 to $0.22 \mathrm{~m}$, which shows less prediction accuracy at high water 


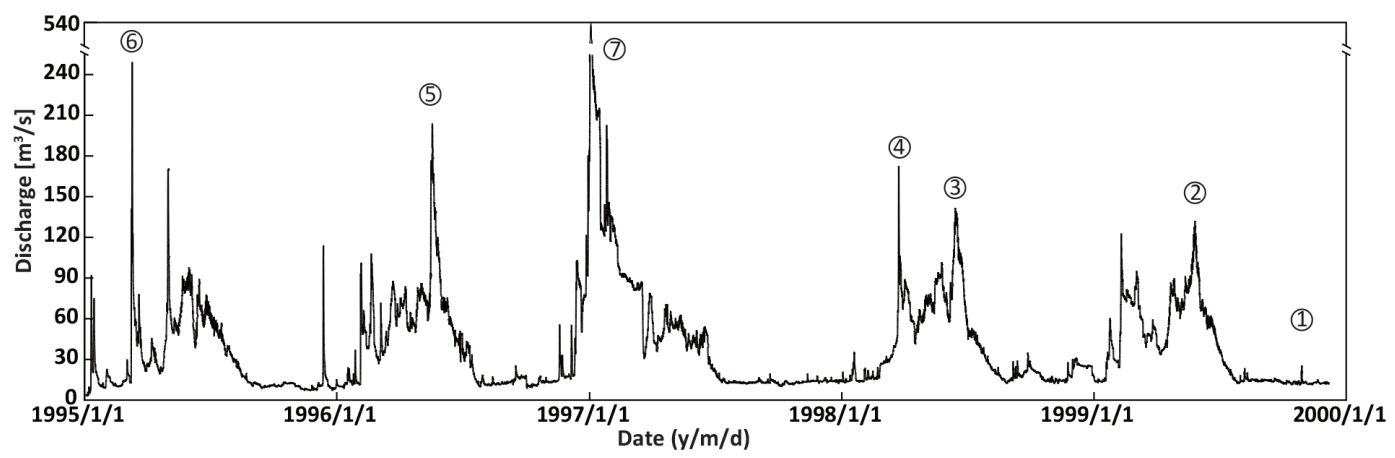

Figure 5. Scenarios of flood events. Cases 6 and 7 represent the 10 and 50 year flood events, respectively.
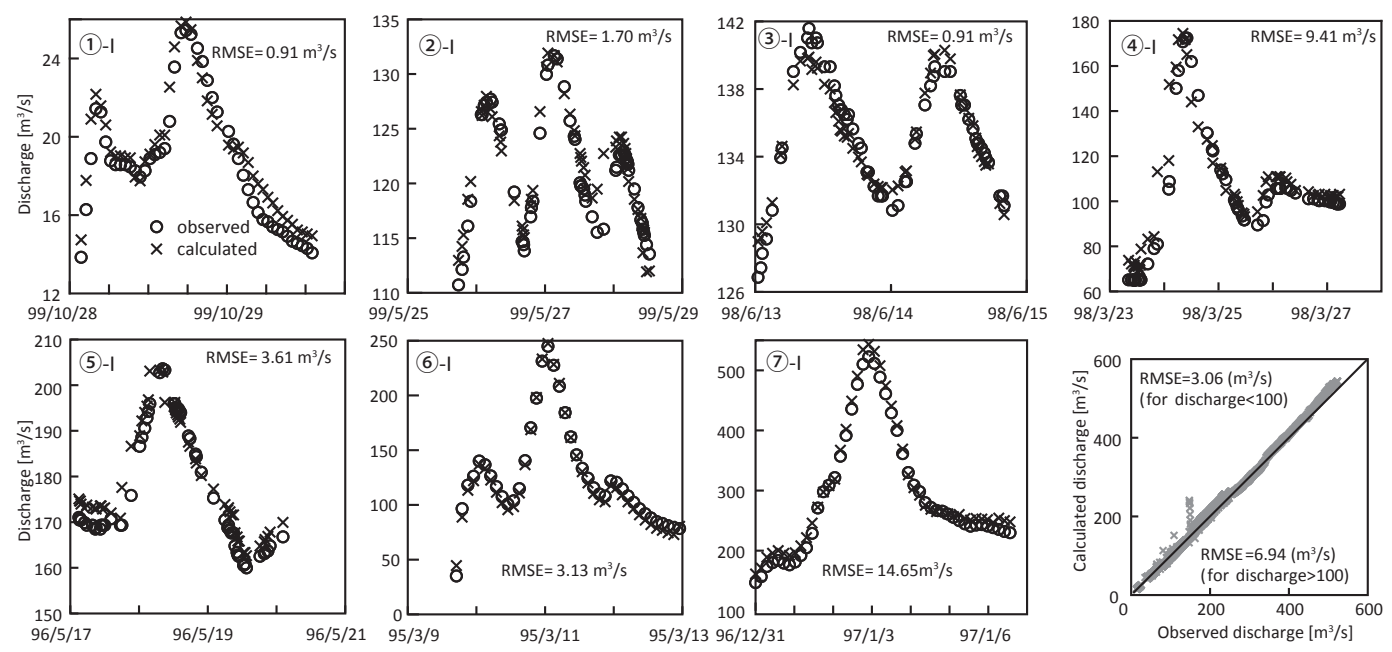

Figure 6. Comparison of calculated discharge and observed discharge.

Table 2. Scenarios of time sensitivity study.

\begin{tabular}{ll}
\hline $\begin{array}{l}\text { Time sensitivity } \\
\text { testing }\end{array}$ & Time step(s) \\
\hline$\Delta t_{1}$ & 1 \\
$\Delta t_{2}$ & 10 \\
$\Delta t_{3}$ & 30 \\
\hline
\end{tabular}

levels. One main cause of the error for water level is likely because of the resolution of the topographic data. The vertical elevations of finite element mesh nodes were interpolated from the coarse DEM $(30 \mathrm{~m})$ on floodplains. Therefore, errors might exist for floodplain delineation. Another source of the error might come from the vertical accuracy of the elevation/bathymetry data. Also, the zoning and spatial properties for each element of the whole modeling domain were primarily based on the land-use data, which generated temporally constant parameters that might not reflect the real conditions. These properties might also affect flow roughness. Although the roughness coefficients had been calibrated for the modeling period, they probably cannot accurately represent the real friction factor of each land-use type at all times (e.g., vegetation properties would change seasonally). Additionally, treating the roughness coefficients as constant values that are independent of flow depth in $\mathrm{AdH}$ modeling would result in errors. In reality, flow roughness can change depending on the water levels over the floodplain (Domeneghetti et al., 2012). Moramarco and Singh (2010) evaluated the trend of Manning's coefficient for two river sites along the Tiber River and they found that the $n$ value decreases with increasing flow depth (and therefore increasing discharge), which shows that there is an asymptotic behavior for high water levels. Furthermore, neglecting both evaporation and infiltration would result in another error. Despite the errors that occur when modeling high flows, the model provides a more detailed view of floodplain hydraulics that can enhance our understanding of water interactions between the main channel and floodplains. 

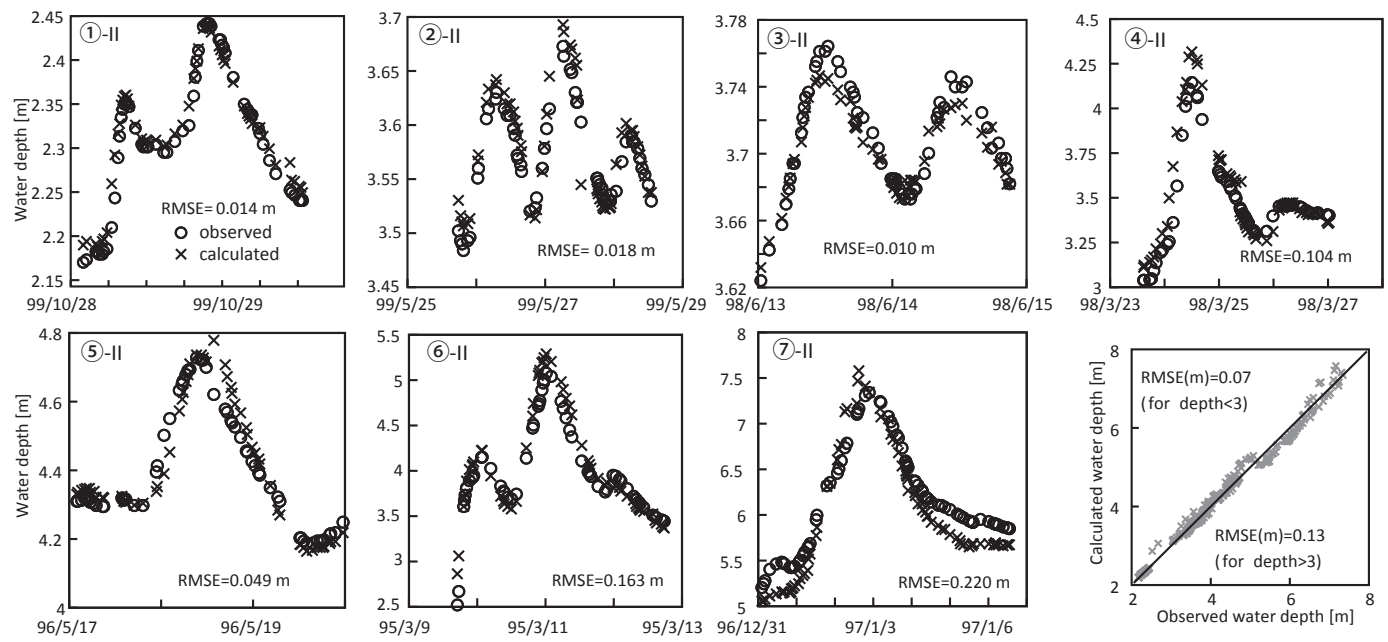

Figure 7. Comparison of calculated water depth and observed water depth.
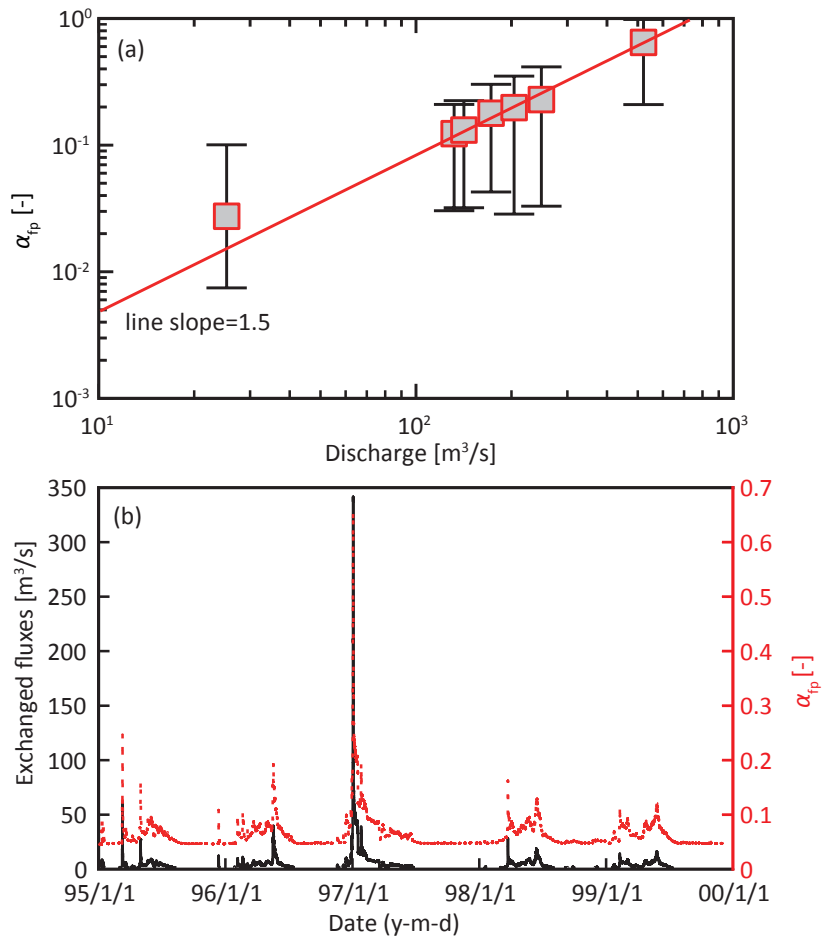

Figure 8. (a) The proportion of total flow that routed through the floodplains $\left(\alpha_{\mathrm{fp}}\right)$ versus inflow discharge. The function of the fitted line is $y=5.0 e-5 x^{1.5}\left(R^{2}=0.984\right)$. (b) The mean value of $\alpha_{\mathrm{fp}}$ for McCarran Ranch from year 1995 to 2000 based on applying the former function in (a).

\subsection{Characterization of exchanges between main channel and floodplains}

We assessed the hydrological connectivity between the main channel and its floodplains using two approaches. First, we examined the spatial variation in the flux distribution at 12 different locations (marked in Fig. 1) along the focused river reach and calculated the averaged longitudinal flux passing through the floodplains $\left(Q_{\mathrm{fp}}\right)$. The proportion of total flow that routed through the floodplains $\left(\alpha_{\mathrm{fp}}\right)$ was then obtained by dividing $Q_{\mathrm{fp}}$ with total discharge. Second, we examined the transboundary flux of both river banks along the focused reach, which is defined as the flow flux penetrating the boundary between the main channel and the floodplains along a selected reach. The transboundary flux ratio $\left(\beta_{\mathrm{ex}}\right)$ was then calculated by dividing the total transboundary flux with inflow discharge.

Quantifying the flux distribution is generally considered a good way to identify the exchange flux and connectivity of the river and the floodplain (Thomaz et al., 2007; Heiler et al., 1995). Previous studies have shown that the lateral exchange can be considerably complicated and strongly depends on channel morphology, and that the magnitudes and direction of lateral flux are spatially related variables. Such exchange cannot be simply described by a single flow quantity, and therefore needs to be examined differently. The proportion of total flow routing through the floodplains $\left(\alpha_{\mathrm{fp}}\right)$ is considered a useful indicator for flux distribution. Its magnitude and spatiotemporal change can disclose some details of the hydraulic role of the floodplains and the interaction between the main channel and the floodplains. For McCarran Ranch, this ratio is calculated at each flux sampling location for seven different discharges, carrying out 84 calculations in total.

The results of the analyses are plotted in Fig. 8a. As shown, the error bars represent the spatial heterogeneity of the flux distribution in the river and floodplain system and the mean values represent the averaged flux proportion that routes through the overall floodplains of the studied reach. The distribution of flux could have been caused by the flow 

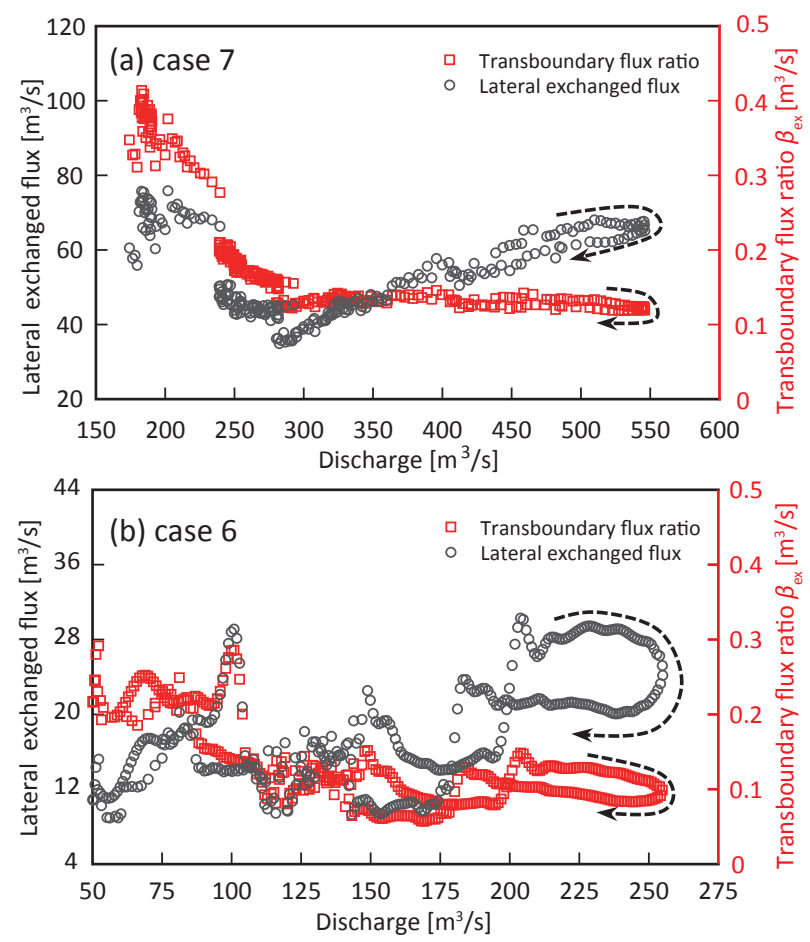

Figure 9. The transboundary flux ratio (or the absolute transboundary flux) versus river discharge of the (a) 50 year flood (case no. 7) and (b) 10 year flood (case no. 6).

pattern of the meandering channel. For example, because transects 6 and 11 (Fig. 1) have stronger meandering features compared with the other transects (e.g., transect 2 is located at a much straighter reach), the flux on the adjacent floodplains can be 3.2-5.3 times that of a straight reach, whereas the peak discharge with the rising flux rate is $248.4 \mathrm{~m}^{3} \mathrm{~s}^{-1}$, which means that the effect of the meandering course is waning. The factor reduces to $2.3-4.1$ when the discharge is as high as $521.3 \mathrm{~m}^{3} \mathrm{~s}^{-1}$. Also, the lateral slope in the terrain could also cause to the flux distribution that is observed in the main channel and floodplain system. Because of the relatively higher slope of hill slopes at transect 1 , the $\alpha_{\mathrm{fp}}$ always has the lowest value compared with the other transects.

The ratio $\alpha_{\mathrm{fp}}$ increases with rising flow discharge. Figure $8 \mathrm{a}$ shows the relationship between the mean proportion and discharge can be fitted with a power-law function (a straight line in logarithmic scales with a slope of 1.5) with a high goodness-of-fit $\left(R^{2}=0.984\right)$. Although this powerlaw relationship for the floodwater exchange ratio was obtained from a specified study reach of Truckee River and might not necessarily be applicable to other sites, it shows that the floods have a significant impact on the flux exchange in a river and floodplain system that would consequently affect the transport of nutrients and organic matter.

The mean value of $\alpha_{\mathrm{fp}}$ for McCarran Ranch from 1995 to 2000 is calculated by applying the power-law function shown in Fig. 8b. Similar to the discharge trend, $\alpha_{\mathrm{fp}}$ fluctuated sea-

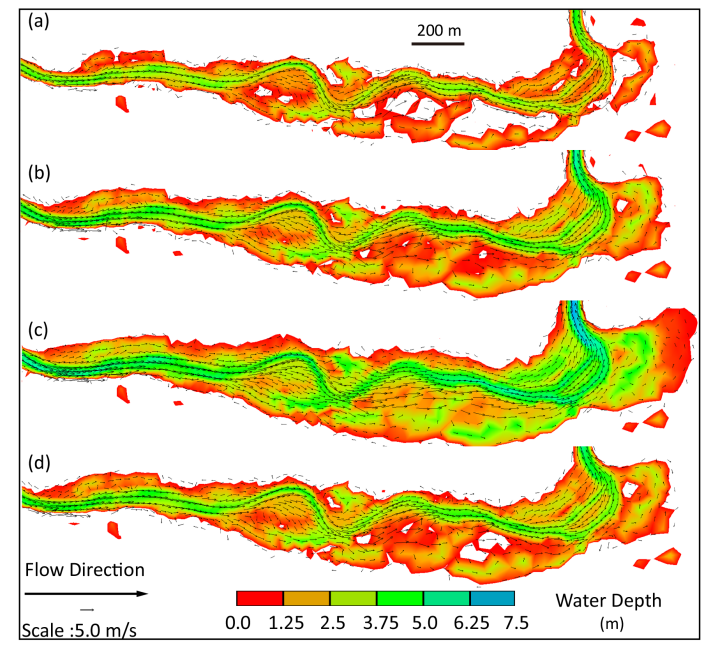

Figure 10. Inundation maps of the 50 year flood event under different flood stages; (a) and (b) are located on the flood rising stage, (c) corresponds to peak discharge, and (d) is located on the flood recession stage.

sonally according to the floods. Generally, the proportion of flux routing through floodplains at McCarran Ranch is less than $5 \%$ during base flow and it can reach approximately 15 to $30 \%$ during small flood events. This ratio can be as high as $65 \%$ during extremely high floods, which represents a much higher proportion of total flow that is routed through the floodplains. Our results are compatible with other results reported in literature. Similar research results have been reported in other river system studies. Richey et al. (1989) used Muskingum routing of main channel flow and simple floodplain representations to estimate the flow volume exchanges in river and floodplain systems at Itapeua of the Amazon River. Their research results showed that the ratio of exchange flux was approximately $30 \%$. Wilson et al. (2007) updated this result based on 2-D modeling and found the ratio to be at least $40 \%$ between Itapeua and Manaus on the Amazon River. Zurbrügg et al. (2012) estimated that the river and floodplain exchange in the Kafue Flats using high-resolution measurements of discharge and tracers. They found the exchange ratio to be as much as $80 \%$ during peak discharge. This river and floodplain exchange results in seasonally recurring sharp changes in dissolved oxygen levels that could greatly impact river quality (Zurbrügg et al., 2012, 2013).

A more direct look of the river and floodplain exchange is the transboundary flux, which is defined as the flow discharge that penetrates the boundary between the main channel and floodplains. The transboundary flux versus river discharge of two particular flood events was plotted in Fig. 9. The fluxes were used to determine the quantity of floodwater from the main channel to the floodplains. Figure 9 shows the maximum transboundary flux that occurred before the peak flow for each flood event. Generally, the transboundary flux ratio is approximately 0.05 to 0.45 and the corresponded 
flux is 8 to $70 \mathrm{~m}^{3} \mathrm{~s}^{-1}$. The variation of transboundary flux is mainly controlled by the magnitude of flood discharge (e.g., when the discharge increases from 270 to $550 \mathrm{~m}^{3} \mathrm{~s}^{-1}$, the total transboundary flux increases from 30 to $65 \mathrm{~m}^{3} \mathrm{~s}^{-1}$ accordingly). The opposite flow across the river boundary at the rising and receding stages leads to the loop curve relation between transboundary flux and discharge.

\subsection{Flood inundation analysis}

The prediction of flood inundation is crucial for risk control and water resources management. Both the inundation area and volume were numerically calculated from the $\mathrm{AdH}$ modeling results. A MATLAB ${ }^{\circledR}$ code was developed for the inundation area and the volume calculation was based on the water depth values on the mesh nodes (outputs of $\mathrm{AdH}$ ) and the finite element mesh information (inputs of $\mathrm{AdH}$ ). The extreme flood event that occurred in early January 1997 was set as an example for inundation analysis. The inundation area and volume were calculated at different discharges that were chosen from the flood rising stage, peak flow stage, and recession stage. Snapshots of the flood inundation maps are illustrated in Fig. 10. Figure 11 shows the scatter plots of the inundation area and inundated volume. The maximum inundation area and volume can be as high as $1.3 \mathrm{~km}^{2}$ and $3.95 \times 10^{6} \mathrm{~m}^{3}$, respectively.

More interestingly, we found that both the inundation area-discharge relation and inundated volume-discharge relation show a looped curve pattern. These looped curves indicate that the same flow discharge at different stages of a flood produced different inundation areas or volumes. This is similar to the looped rating curve for the stage-discharge relation during flood events. Based on the literature survey, the looped curve pattern of the inundation area or volume-discharge relation had not been reported in the previous studies. This result is useful for flood risk mitigation, as well as improving flood disaster assessments and risk estimations. Furthermore, the inundation area-discharge relation describes an areal result rather than a result at a station (i.e., it is an upscaled result of the point-scale stage-discharge relation). It shows that this hysteresis can appear not only at local scales, but also at large spatial scales, which can help us further understand the flood regime and its related biogeochemical processes.

\section{Implications on riverine ecosystems and flood management}

This study reveals the hydrological connectivity of the main channel and floodplain system of Truckee River during flood events. As discussed in the previous section, the channel divides a considerable portion of its inflow into the floodplains. The lateral water exchanges between the main channel and floodplain are closely related to the discharge fluctuations, which show an intensive heterogeneity under differ-

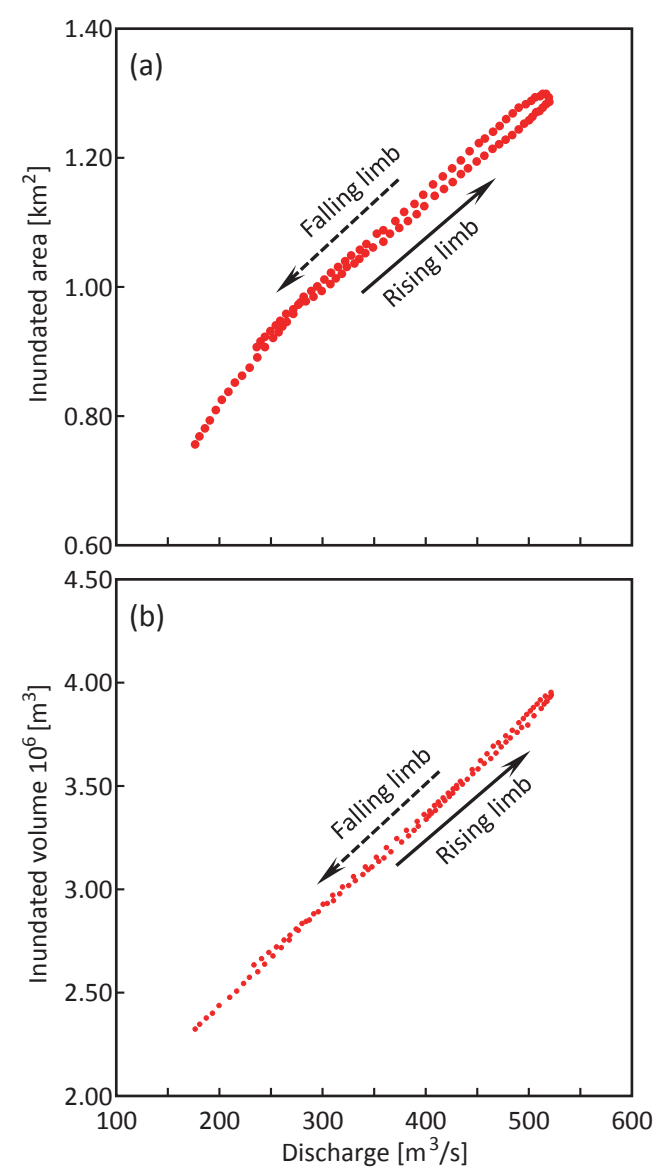

Figure 11. The scatter plots of inundation area versus discharge (a) and inundated volume versus discharge (b) of a sample flood event.

ent spatio-temporal scales. This high level of spatio-temporal heterogeneity makes riverine floodplains one of the most species-rich environments (Ward et al., 1999). We have analyzed the hydraulic roles of floodplains quantitatively through a set of characterizing parameters $\left(\alpha_{\mathrm{fp}}\right.$ and $\left.\beta_{\mathrm{ex}}\right)$ because the hydrodynamics of flooding play a dominant role in maintaining a diversity of lentic, lotic, and semiaquatic habitat types (Ward et al., 1999; Amoros and Bornette, 2002).

During flood events, floodwater sweeps onto the river bank, carrying with it large amounts of upstream sediment (organic or inorganic substances). When the hydraulic condition meets the appropriate water and sediment dynamic conditions, sediments are deposited on the floodplains. This process provides conditions for floodplain wetlands material recycling. Additionally, aquatic organisms (fish, invertebrates, plankton, etc.) would be entrained into the low-lying zones and eventually participate in the local food chain activities (Stanford and Ward, 1993; Tockner et al., 1999). Biochemical processes, such as metabolism activities, that happen on patches of floodplain would not change much until the next flood pulse (Thoms, 2003). 
The ecological health of the river corridor relies not only on the surface water hydrological connection, but also on the surface-subsurface water interactions (i.e., hyporheic exchanges). Although we have only discussed the flood hydrodynamic process on the Truckee River, we can still speculate that the intense flood inundations and transient fluctuations will certainly affect subsurface flow within the riparian zone. For instance, the lateral hyporheic flow patterns. Recent studies have shown that hyporheic exchanges within the river and floodplain system play a key role in maintaining the health of fluvial systems because of its control of biogeochemical and ecological processes (Boulton and Hancock, 2006; Boulton et al., 1998; Brunke and Gonser, 1997; Findlay, 1995). The flood will cause a much higher inundation area. This implies that the hyporheic exchanged zone will extend to a larger configuration according to the inundation. Therefore, it will affect the biogeochemical processes in the riverbed and floodplain. For example, the nitrification processes in the downwelling area and the denitrification processes in the upwelling zone (Findlay, 1995).

Our results also indicated an interesting hysteresis pattern to flood inundation behavior. The largest inundation area/volume occurred behind the peak discharge. Because of the unsteady fluctuation rate, backwaters in bend area, heterogeneity of lateral exchanges, and other factors, the flood propagation generally shows strong nonlinear dynamics. Therefore, the maximum loss caused by a certain flood event will lag behind the peak discharge. This implies that when we are evaluating a disastrous flood, it is more appropriate to incorporate the hysteresis pattern.

\section{Conclusions}

The AdH model is an effective method for delineating flood inundation in areas of subtle topographic relief. This model was used to simulate flooding at McCarran Ranch on the Truckee River with a much finer mesh grids. The model was calibrated with gauge data and the validated model performed well in representing the flood hydrographs of various magnitudes. Although the accuracy of prediction declined slightly at higher discharge and water stages, the raw output of depth and velocity magnitudes from 2-D, AdH modeling appears adequate to produce reasonable results.

Results show that the proportion of flow that routed through the floodplains is much higher during extreme flood events. Because the river and floodplain exchange plays a crucial role in maintaining ecosystem, estimating the exchange ratio through a modeling approach could be useful for river restoration and river landscape design, or even as a global index for river ecological assessment. However, field measurements are still recommended for further verification of AdH modeling results.

The inundation area (or volume)-discharge relation at McCarran Ranch on Truckee River was found to be a loop curve pattern, which showed that hysteresis of flood inundation exists on large spatial scales. Although this result was obtained from a specific river reach, it will be potentially useful for flood risk assessment and water resources management of other river and floodplain systems, especially for rivers with considerably more floodplain areas.

Acknowledgements. The work was funded by U.S. Army Corps of Engineering (W912HZ-08-2-0021) and partially funded by the National Natural Science Foundation of China (41401014; 51279045; 51425901) and China Postdoctoral Science Foundation (2015M570402). Thanks to Eleeja Shrestha for assistance with data collection. The authors are grateful to the editor Paolo Tarolli and the two anonymous reviewers for their insightful comments which have helped to improve the quality of the paper. Results of the models are available from the corresponding author upon request.

Edited by: P. Tarolli

Reviewed by: three anonymous referees

\section{References}

Abderrezzak, K. E. K., Paquier, A., and Mignot, E.: Modelling flash flood propagation in urban areas using a two-dimensional numerical model, Nat. Hazards, 50, 433-460, 2009.

Amoros, C. and Bornette, G.: Connectivity and biocomplexity in waterbodies of riverine floodplains, Freshwater Biol., 47, 761776, 2002.

Antheunisse, A. M. and Verhoeven, J. T.: Short-term responses of soil nutrient dynamics and herbaceous riverine plant communities to summer inundation, Wetlands, 28, 232-244, 2008.

Bates, P. D. and De Roo, A. P. J.: A simple raster-based model for flood inundation simulation, J. Hydrol., 236, 54-77, 2000.

Bates, P. D., Horritt, M. S., and Fewtrell, T. J.: A simple inertial formulation of the shallow water equations for efficient twodimensional flood inundation modelling, J. Hydrol., 387, 33-45, 2010.

Bayley, P. B.: Understanding large river: floodplain ecosystems, Biosci., 45, 153-158, 1995.

Birkett, C. M., L. A. K. Mertes, T. Dunne, M. H. Costa, and M. J. Jasinski: Surface water dynamics in the Amazon Basin: Application of satellite radar altimetry, J. Geophys. Res., 107, LBA 26-1-LBA 26-21, doi:10.1029/2001JD000609, 2002.

Boulton, A. J. and Hancock, P. J.: Rivers as groundwater-dependent ecosystems: a review of degrees of dependency, riverine processes and management implications, Aust. J. Bot., 54, 133-144, 2006.

Boulton, A. J., S. Findlay, P. Marmonier, E. H. Stanley, and H. M. Valett: The functional significance of the hyporheic zone in streams and rivers, Annu. Rev. Ecol. Syst., 29, 59-81, 1998.

Bridge, J. S.: Rivers and Floodplains: Forms, Processes and Sedimentary Record, 491 pp., Blackwell, Malden, Mass, 2003.

Brunke, M. and Gonser, T. O. M.: The ecological significance of exchange processes between rivers and groundwater, Freshwater Biol., 37, 1-33, 1997.

Chow, V., Maidment, D. R., and Mays, L. W.: Applied hydrology, Tata McGraw-Hill Education, 35, 1988 
Coe, M. T. and Birkett, C. M.: Calculation of river discharge and prediction of lake height from satellite radar altimetry: Example for the Lake Chad basin, Water Resour. Res., 40, W10205, doi:10.1029/2003WR002543, 2004.

deAlmeida, G. A. M., Bates, P., Freer, J. E., and Souvignet, M.: Improving the stability of a simple formulation of the shallow water equations for 2-D flood modeling, Water Resour. Res., 48, W05528, doi:10.1029/2011WR011570, 2012.

Domeneghetti, A., Castellarin, A., and Brath, A.: Assessing ratingcurve uncertainty and its effects on hydraulic model calibration, Hydrol. Earth Syst. Sci., 16, 1191-1202, doi:10.5194/hess-161191-2012, 2012.

Findlay, S.: Importance of surface-subsurface exchange in stream ecosystems: the hyporheic zone, Limnol. Oceanogr., 40, 159164,1995

Frappart, F., Seyler, F., Martinez, J. M., León, J. G., and Cazenave, A.: Floodplain water storage in the Negro River basin estimated from microwave remote sensing of inundation area and water levels, Remote Sens. Environ., 99, 387-399, 2005.

Galat, D. L.: Seasonal and long-term trends in Truckee River nutrient concentrations and loadings to Pyramid Lake, Nevada: A terminal saline lake, Water Res., 24, 1031-1040, 1990.

Gambucci, T.: ADH = Fast and Stable 2D Finite Element Model, in: Proceedings of World Environmental \& Water Resources Congress, 2816-2822, 2009.

Hamilton, S. K., Sippel, S. J., and Melack, J. M.: Comparison of inundation patterns among major South American floodplains, J. Geophys. Res., 107, LBA 5-1-LBA 5-14, doi:10.1029/2000JD000306, 2002.

Hamilton, S. K., Sippel, S. J., and Melack, J. M.: Seasonal inundation patterns in two large savanna floodplains of South America: the Llanos de Moxos (Bolivia) and the Llanos del Orinoco (Venezuela and Colombia), Hydrol. Process., 18, 2103-2116, doi:10.1002/hyp.5559, 2004.

Heiler, G., Hein, T., Schiemer, F., and Bornette, G.: Hydrological connectivity and flood pulses as the central aspects for the integrity of a river-floodplain system, Regulated Rivers: Research and Management, 11, 351-361, 1995.

Hess, L. L., Melack, J. M., Novo, E. M., Barbosa, C. C., and Gastil, M.: Dual-season mapping of wetland inundation and vegetation for the central Amazon basin, Remote Sens. Environ., 87, 404$428,2003$.

Hunter, N. M., Bates, P. D., Horritt, M. S., and Wilson, M. D.: Simple spatially-distributed models for predicting flood inundation: a review, Geomorphology, 90, 208-225, 2007.

Karadogan, E. and Willson, C. S.: Simulating the impact of medium and large diversions on the hydrodynamics in the lower Mississippi River Delta, in: River Flow 2010 Proceedings of the International Conference on Fluvial Hydraulics, edited by: Dittrich, Koll, Aberle, and Geisenhainer, 1581-1588, 2010.

Krause, P., Boyle, D. P., and Bäse, F.. Comparison of different efficiency criteria for hydrological model assessment, Advances in Geosciences, 5, 89-97, 2005.

Leopardi, A., Oliveri, E., and Greco, M.: Two-dimensional modeling of floods to map risk-prone areas, J. Water Resour. Plann. Manage., 128, 168-178, 2002.

McCuen, R. H., Knight, Z., and Cutter, A. G.: Evaluation of the Nash-Sutcliffe efficiency index, J. Hydrol. Eng., 11, 597-602, 2006.
McKenna, S. A., Ingraham, N. L., Jacobson, R. L., and Cochran, G. F.: A stable isotope study of bank storage mechanisms in the Truckee river basin, J. Hydrol., 134, 203-219, 1992.

Mignot, E., Paquier, A., and Haider, S.: Modeling floods in a dense urban area using 2D shallow water equations, J. Hydrol., 327, 186-199, 2006.

Moramarco, T. and Singh, V. P.: Formulation of the entropy parameter based on hydraulic and geometric characteristics of river cross sections, J. Hydrol. Eng., 15, 852-858, 2010.

Nash, J. and Sutcliffe, J. V.: River flow forecasting through conceptual models part I-A discussion of principles, J. Hydrol., 10, 282-290, 1970.

Neal, J., Schumann, G., Fewtrell, T., Budimir, M., Bates, P., and Mason, D.: Evaluating a new LISFLOOD-FP formulation with data from the summer 2007 floods in Tewkesbury, UK, J. Flood Risk Manag., 4, 88-95, 2011.

Neal, J., Villanueva, I., Wright, N., Willis, T., Fewtrell, T., and Bates, P.: How much physical complexity is needed to model flood inundation?, Hydrol. Process., 26, 2264-2282, 2012.

Overton, I. C.: Modelling floodplain inundation on a regulated river: integrating GIS, remote sensing and hydrological models, River Res. Appl., 21, 991-1001, 2005.

Pettit, N. E., Bayliss, P., Davies, P. M., Hamilton, S. K., Warfe, D. M., Bunn, S. E., and Douglas, M. M.: Seasonal contrasts in carbon resources and ecological processes on a tropical floodplain, Freshwater Biol., 56, 1047-1064, 2011.

Richey, J. E., Mertes, L. A. K., Dunne, T., Victoria, R. L., Forsberg, B. R., Tancredi, A. C. N. S., and Oliveira, E.: Source and routing of the Amazon River flood wave, Global Biogeochem. Cy., 3, 191-204, 1989.

Rodi, W.: Turbulance Models and Their Application in Hydraulics: A State-Of-The-Art Review, Taylor \& Francis Group, Balkema, Leiden, 33-43, 1993.

Sheldon, F., Boulton, A. J., and Puckridge, J. T.: Conservation value of variable connectivity: aquatic invertebrate assemblages of channel and floodplain habitats of a central Australian aridzone river, Cooper Creek, Biol. Conserv., 103, 13-31, 2002.

Stanford, J. A. and Ward. J. V.: An Ecosystem Perspective of Alluvial Rivers: Connectivity and the Hyporheic Corridor, J. N. Am. Benthol. Soc., 12, 48-60, 1993.

Tate, J., McAlpin, T. O., and Savant, G.: Modeling Dam/Levee Breach Scenarios Using the ADaptive Hydraulics Code. 2009 AWRA Annual Water Resources Conference, Seattle, Washington, 250 pp., 2009.

Thomaz, S. M., Bini, L. M., and Bozelli, R. L.: Floods increase similarity among aquatic habitats in river-floodplain systems, Hydrobiologia, 579, 1-13, 2007.

Thoms, M. C.: Floodplain-river ecosystems: lateral connections and the implications of human interference, Geomorphology, 56, 335-349, 2003.

Tockner, K., Pennetzdorfer, D., Reiner, N., Schiemer, F., and Ward, J. V.: Hydrological connectivity, and the exchange of organic matter and nutrients in a dynamic river-floodplain system (Danube, Austria), Freshwater Biol., 41, 521-535, 1999.

Townsend, P. A. and Walsh, S. J.: Modeling floodplain inundation using an integrated GIS with radar and optical remote sensing, Geomorphology, 21, 295-312, 1998. 
Ward, J. V., Tockner, K., and Schiemer, F.: Biodiversity of floodplain river ecosystems: ecotones and connectivity, Regulated Rivers: Research \& Management, 15, 125-139, 1999.

Wilson, M., Bates, P., Alsdorf, D., Forsberg, B., Horritt, M., Melack, J., Frappart, F., and Famiglietti, J.: Modeling large-scale inundation of Amazonian seasonally flooded wetlands, Geophys. Res. Lett., 34, L15404, doi:10.1029/2007GL030156, 2007.
Zurbrügg, R., Wamulume, J., Kamanga, R., Wehrli, B., and Senn, D. B.: River-floodplain exchange and its effects on the fluvial oxygen regime in a large tropical river system (Kafue Flats, Zambia), J. Geophys. Res., 117, G03008, doi:10.1029/2011JG001853, 2012.

Zurbrügg, R., Suter, S., Lehmann, M. F., Wehrli, B., and Senn, D. B.: Organic carbon and nitrogen export from a tropical dam-impacted floodplain system, Biogeosciences, 10, 23-38, doi:10.5194/bg-10-23-2013, 2013. 